\title{
Efficiency in Centralized DC Systems Compared with Distributed DC Systems in Photovoltaic Energy Conversion
}

\author{
Mehmet Ali Ozcelik ${ }^{1}$, Ahmet Serdar Yilmaz ${ }^{2}$, Selahattin Kucuk ${ }^{3}$, Mehmet Bayrak ${ }^{4}$ \\ ${ }^{I}$ Department of Electric, Vocational School of Technical Sciences, Gaziantep University, \\ Gaziantep, Turkey \\ ${ }^{2}$ Department of Electrical and Electronics Engineering, Sutcu Imam University, \\ Kahramanmaras, Turkey \\ ${ }^{3}$ Tupras Turkish Petroleum Refineries Company, \\ Izmit, Turkey \\ ${ }^{4}$ Department. of Electrical and Electronics Engineering, Sakarya University, \\ Sakarya, Turkey \\ ozcelik@gantep.edu.tr
}

\begin{abstract}
Photovoltaic (PV) systems produce a significant amount of electrical energy used around the world. The performance of a $\mathrm{PV}$ array is affected by temperature, solar insolation, shading and array configuration. Obtainable maximum power generation from PV based energy production systems is only possible with Maximum Power Point Tracking (MPPT) methods. In order to maximize the efficiency of PV energy conversion systems, solar panels and arrays should be operated at maximum power points. At maximum power point, solar arrays generate the electric energy at maximum efficiency and minimum losses. This paper discusses the following issues: (1) what is the effect of MPPT unit in PV systems, (2) two connection methods between solar arrays and buck-boost DC/DC converter with MPPT unit, (3) determine behaviours of $P V$ power generation systems in cloudy and sunny conditions.
\end{abstract}

Index Terms-DC-DC power converters, maximum power point tracking, $\mathrm{P} \& O$ algorithm, solar power generation.

\section{INTRODUCTION}

Obtaining maximum power and reaching highest efficiency level in photovoltaic panels is an important research topic [1], [2]. Solar cells have variable current and voltage characteristics and maximum power point depends on solar irradiations and ambient temperature. MPPT is developed to capture maximum power level in variable atmospherically conditions [3], [4]. DC/DC converters are most important devices of PV systems which converts the direct current power output for battery charge or DC loads.

$\mathrm{PV}$ panels have mono crystalline structure which is arranged in a one by one configuration to form a $10 \mathrm{~W}$ power solar array. The output power from the arrays were converted to DC power with buck-boost converter types. Both of the topologies use a common DC/DC converter with

Manuscript received December 18, 2014; accepted June 30, 2015.

This research was supported by the Sutcu Imam University, Administration of Scientific Research Project Coordination Unit (Project Number: 2013/2-38M) in 2013. different their MPPT structure. Firstly, two PV panels were connected to a centralized MPPT buck-boost converter. Secondly, each panel was connected to a MPPT buck-boost converter in the same PV array configuration.

In order to find the effects of various connect PV panels, the PV panels were applied by the light from a halogen lamp. The halogen lamp in this case was to symbolise light whereas the case where some part of the PV is covered with a dark object is to symbolise the cloudy condition. In both cases the current and voltage changes were observed. The outputs were compared in order to define the correct DC/DC converter with MPPT unit layout for an optimal position.

This article examines the various in efficiency, stability and quality of energy conversion for solar systems in unsteady conditions. Especially, the effects of changeable irradiation over a PV arrays were observed on two alternative modelled systems in order to determine which topology performed better in variable conditions. To do it, two solar energy conversion systems were experimented. Also, by utilizing MATLAB simulation, the effects of MPPT in photovoltaic energy conversion were assessed.

\section{THEORETICAL BACKGROUND}

As the sun light hits on PV cells, photo-voltage and photocurrent acts like a forward diode on a large surface. The current expression as a result of the sunlight hitting on the cell is given in (1) [5]

$$
I=I_{P H}-I_{S} \times\left\{\exp \left[\frac{q}{A k T}\left(V+I R_{L}\right)\right]-1\right\}-\frac{V+I R_{S}}{R_{S H}} .
$$

In this expression, photo-current, saturation current, load resistance, series equivalent circuit resistance, parallel equivalent circuit resistance, terminal voltage, load current, diode ideality factor, Boltzman's constant and temperature of PV panel are denoted by $\mathrm{I}_{\mathrm{PH}}, \mathrm{I}_{\mathrm{S}}, \mathrm{R}_{\mathrm{L}}, \mathrm{Rs}, \mathrm{R}_{\mathrm{SH}}, \mathrm{V}, \mathrm{I}, \mathrm{A}, \mathrm{k}$ 
and $\mathrm{T}$ respectively. The equivalent circuit diagram for a solar cell is shown in Fig. 1.

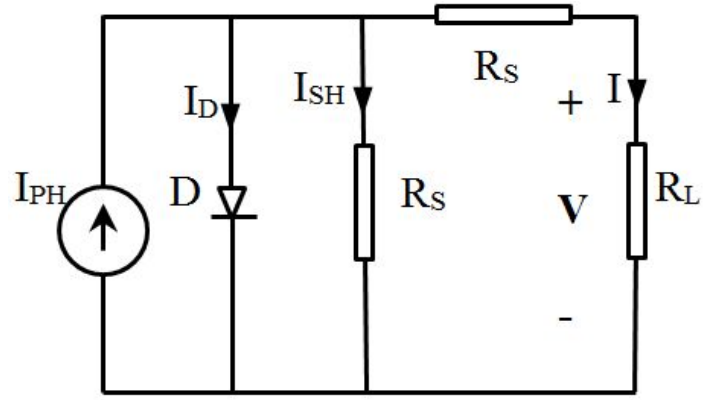

Fig. 1. Equivalent circuit diagram for solar cells.

PV panels, which are created through series or parallel connected solar cells, are electrically comprised of a current source, series and parallel resistances and parallel diodes. The relation between the voltage of solar cells and current switched on the load exposes I-V and P-V characteristics of the cell. These two characteristics give important indications regarding which conditions are required in order for the power obtained from the panel to reach its maximum level. Achieving the maximum power and reaching highest efficiency level in these panels is an important research topic. Solar panels act like a current source while, from a certain point onward, they act like a voltage source. Current value that can be obtained from a solar panel is established in the case of a short circuit. This value is given along with the nameplate value of the panel. It is necessary to obtain maximum power from PV panels in any insolation condition. Maximum power point for PV systems varies depending on atmospheric conditions, which are ambient temperature and insolation amount. In general, PV solar panels reach their maximum power point at around $25{ }^{\circ} \mathrm{C}$. Insolation amount is defined as the sunlight power per unit area. Electrical parameters of the photovoltaic panel simulated and experimented in this study are given in Table I and Table II. Figure 2 also illustrates the I-V and P-V characteristics of this PV panel.

TABLE I. ELECTRICAL PARAMETERS OF SIMULATED PV ARRAY.

\begin{tabular}{|c|c|}
\hline Module specifications under STC & Parameters \\
\hline Maximum power at $1000 \mathrm{~W} / \mathrm{m}^{2}(\mathrm{Pmp})$ & $85.0 \mathrm{~W}$ \\
\hline Open-circuit voltage (Voc) & $22.2 \mathrm{~V}$ \\
\hline Short-circuit current (Isc) & $5.45 \mathrm{~A}$ \\
\hline Voltage at Pmax (Vmp) & $17.2 \mathrm{~V}$ \\
\hline Current at Pmax (Imp) & $4.95 \mathrm{~A}$ \\
\hline
\end{tabular}

TABLE II. ELECTRICAL PARAMETERS OF PV PANEL IN THE EXPERIMENTAL SETUP (TPS-105 MONO CRYSTALLINE).

\begin{tabular}{|c|c|}
\hline Module specifications under STC & Parameters \\
\hline Maximum power at $1000 \mathrm{~W} / \mathrm{m}^{2}(\mathrm{Pmp})$ & $10.0 \mathrm{~W}$ \\
\hline Open-circuit voltage $(\mathrm{Voc})$ & $21.0 \mathrm{~V}$ \\
\hline Short-circuit current $(\mathrm{Isc})$ & $0.66 \mathrm{~A}$ \\
\hline Voltage at Pmax (Vmp) & $16.8 \mathrm{~V}$ \\
\hline Current at Pmax (Imp) & $0.60 \mathrm{~A}$ \\
\hline
\end{tabular}

To obtain maximum efficiency solar panel should be operated at that point. Maximum power formula can be expressed as

$$
P_{m p}=I_{m p} \cdot V_{m p}
$$

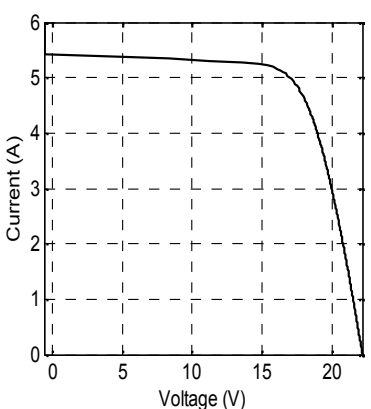

(a)

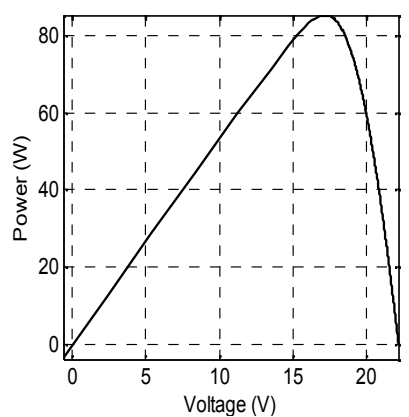

(b)
Fig. 2. Typical characteristics of simulated PV array: a) I-V curve, (b) P-V curve.

Buck-boost converter, as its name entailed, is a structure that decrease and increase the voltage. Similarly to the boost converter there appear the two stroke transfers of energy from the power source to the electric load. Its simplified circuit diagram is shown in Fig. 3. In PV systems, input voltage defined as $V_{S}$ is the panel output voltage, $V_{O}$ is the battery or load voltage and $\mathrm{d}$ is duty cycle which are given in (3) [6], [7].

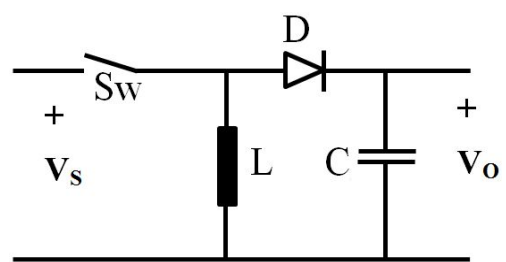

Fig. 3. Circuit diagram for Buck-Boost DC/DC converter.

During the switching (MOSFET) component turns on, the inductor receives energy from the input source and the reverse-biased diode disconnects the source from the load. In this mode the load energy is supplied by the output capacitor as in the boost converter case. When it turns off, the diode (D) becomes forward biased and takes the inductor current and the stored energy in the inductor is delivered to the load. Since the inductor current is in reverse direction, the load also receives the output current in the reverse direction, unlike the formerly introduced converters.

Hence, the output voltage of the buck-boost converter will have reverse polarity in comparison to its input. The voltage conversion ratio can be obtained by applying the voltagetime balance rule which is shown from the following equation

$$
\frac{V_{o}}{V_{s}}=\frac{d}{1-d}
$$

\section{Perturbation AND ObSERVE Algorithm}

Perturbation and Observe (P\&O) algorithm is most commonly used in practical experiments due to its simplicity. It enables to make a decision through analysing the change in output power following experimental voltage increase and decrease in PV system. This algorithm is also known as hill climbing. P-V curve in PV panel is used in this algorithm. The amount of power change $(\Delta \mathrm{P})$ in $\mathrm{PV}$ panel is 
measured after a minimal increase. If the power change $(\Delta \mathrm{P})$ value is positive, operating voltage is increased again, which causes PV panel operating point to come its maximum power point. That is to say, the output voltage is watched constantly and it is determined whether to decrease or increase reference after a relation between control variable and power actions is installed. This algorithm and changing rates are given in Table III [8].

TABLE III. SUMMARY OF P\&O ALGORITHM.

\begin{tabular}{|c|c|c|}
\hline Perturbation & Power Change & Next Perturbation \\
\hline Positive & Positive & Positive \\
\hline Positive & Negative & Negative \\
\hline Negative & Positive & Negative \\
\hline Negative & Negative & Positive \\
\hline
\end{tabular}

The PV operating point is perturbed periodically by changing the voltage at PV source terminals, and after each perturbation the control algorithm compares the values of the power by the PV before and after the perturbation. Hence the perturbation of the PV power has increased, this means that the operating point has performed toward the MPP (Maximum Power Point). As a result, the next perturbation imposed to the voltage will have the same sign as the previous one [9]. Because of following voltage perturbation of the PV array decreases, this denotation that the operating point has been acted away from the MPP. Block diagram for implementing the Perturb and Observe algorithm in PV system is shown in Fig. 4.

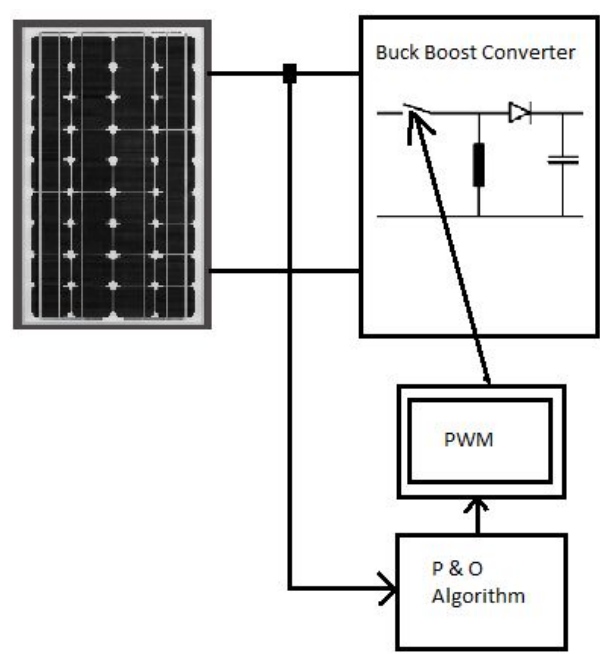

Fig. 4. Block for implementing the $\mathrm{P} \& \mathrm{O}$ algorithm in $\mathrm{PV}$ system.

Thus, the sign of the next voltage perturbation is inverted; the switch in converter is utilized to drive the perturbation of the operating voltage of the PV panel. The basic P\&O configuration can be applied for the switching component (Mosfet) and carry out the PV panel voltage perturbation. The first one causes a direct perturbation of the duty ratio of the DC/DC converter power. In the second one the perturbation is experimented to the reference voltage of the duty cycle. The answer can be seen from Fig. 4. In this case, the buck boost converter operates in open loop next each duty cycle perturbation. The general definition of the $\mathrm{P} \& \mathrm{O}$ algorithm is given in (4) [10]

$$
\begin{gathered}
x\left[(k+1) \times T_{p}\right]=x\left(k \times T_{p}\right) \pm \Delta x=x\left(k \times T_{p}\right)+ \\
+\left\{x\left(k \times T_{p}\right)-x\left[(k-1) \times T_{p}\right]\right\} \times \\
\quad \times \operatorname{sign}\left\{P(k \times T p)-P\left[(k-1) \times T_{p}\right]\right\},
\end{gathered}
$$

where $x$ presents the variable which is perturbed, $T p$ is the time interval between two perturbations, in the continuation intend to as perturbation period, $x$ is the magnitude of the perturbation subjected to $x$, in the continuation intend to as perturbation magnitude, and $\mathrm{P}$ is the power drawn from the PV panels.

Figure 5 shows the flowchart of the $\mathrm{P} \& \mathrm{O}$ algorithm based on (4). The basic adaptation of the P\&O algorithm utilizations a stable step amplitude $x$ that is chosen on the essential of action exchange between temporary rise time and stable state [10].

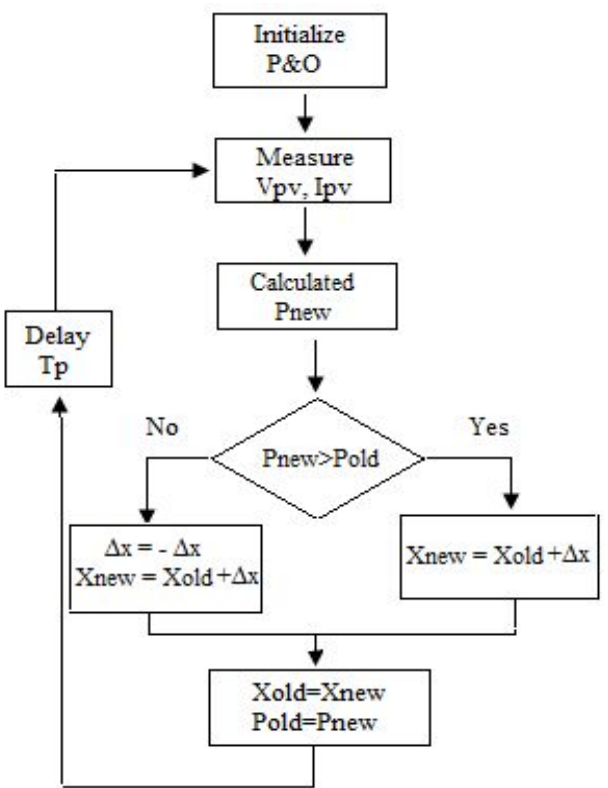

Fig. 5. Basic flowchart for implementing the $\mathrm{P} \& \mathrm{O}$ algorithm [10].

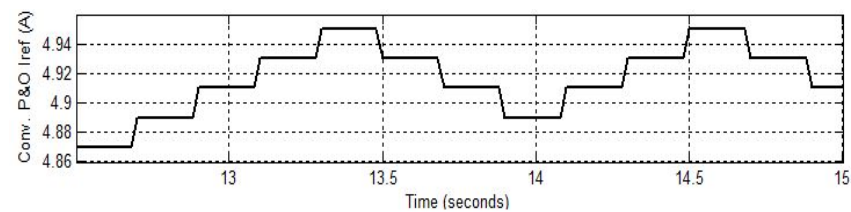

Fig. 6. PV training points subjected by the $\mathrm{P} \& \mathrm{O}$ algorithm.

Figure 6 shows the operating points of the PV field subjected step by step by the $\mathrm{P} \& \mathrm{O}$ algorithm which the perturbing form of the $\mathrm{P} \& \mathrm{O}$ and other same MPPT algorithms. The $\mathrm{P} \& \mathrm{O}$ algorithm can be confused and the operating point can become indecisive, incoming irregular or chaotic form [11]. Unlike, a very big value of $\mathrm{Tp}$ comes down on the MPPT rate.

\section{EFFECT OF MPPT ON EFFICIENCY}

Different initial radiation values were examined for two different operating points in the simulations. First, the sample evaluation for constant reference current was performed without using MPPT. Then the comparison between output power and efficiency has been done with the same case study using MPPT unit. All simulations are 
carried out by using Simulink model [5] which is seen in Fig. 7.

\section{A. Case A: Operating of the System without MPPT}

It is possible to use the same model by switching element on-off according to the cases with MPPT and without MPPT. In initial operation without MPPT starts with an illumination value of $1000 \mathrm{~W} / \mathrm{m}^{2}$ and then increased $1050 \mathrm{~W} / \mathrm{m}^{2}$ at 50 th second. The output results of the simulation without MPPT are given in Fig. 7.
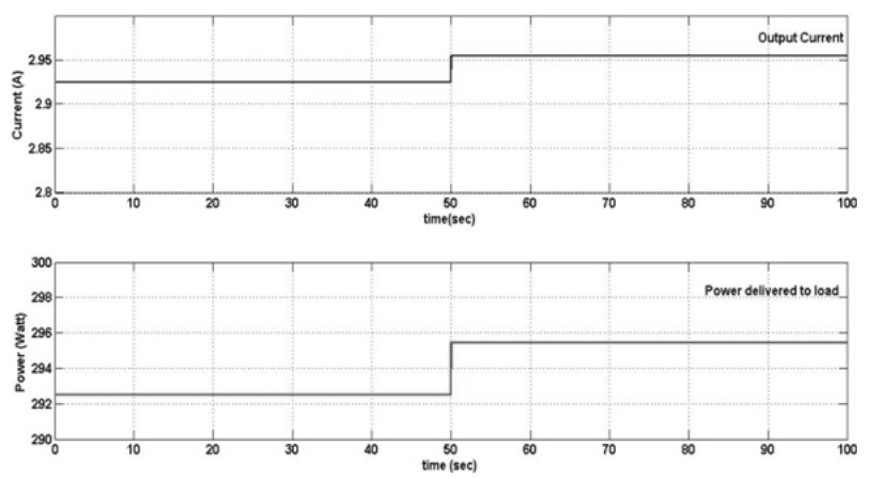

Fig. 7. Output current and power without MPPT.

\section{B. Case B: Operating of System with MPPT}

In the same case of study, output powers and currents analysed according to current reference that can be changed by illumination level with MPPT. P\&O algorithm is written as Matlab code and the outputs are given in Fig. 8.
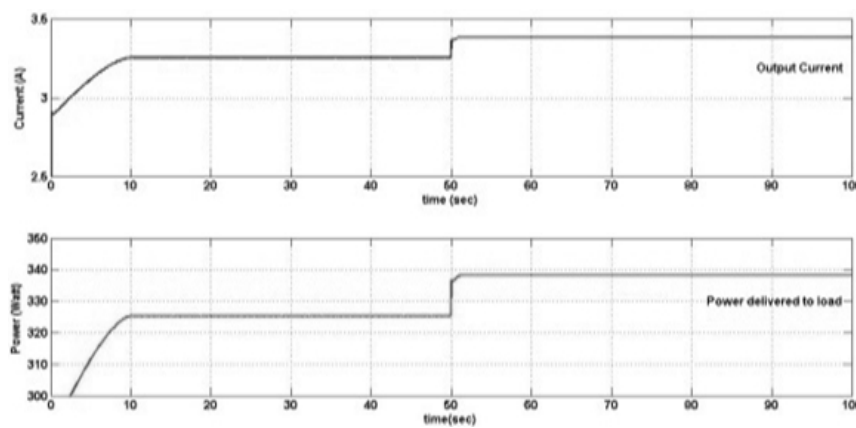

Fig. 8. Current and power output with MPPT.

The comparison of output powers provides better understanding. Initially in $1000 \mathrm{~W} / \mathrm{m}^{2}$ illumination value, load absorbed 325.3 W with MPPT and 292.5 W without MPPT. At 50 second when illumination value increased by $50 \mathrm{~W} / \mathrm{m}^{2}$ load absorbs $338.2 \mathrm{~W}$ with MPPT, $295.5 \mathrm{~W}$ without MPPT. To understand the difference better, output powers at different illumination values is analysed and results are given in Table IV.

TABLE IV. OUTPUT POWERS AT DIFFERENT ILLUMINATION

\begin{tabular}{|c|c|c|c|c|c|}
\hline \multicolumn{6}{|c|}{ VALUES. } \\
\hline $\mathrm{W} / \mathrm{m}^{2}$ & $\begin{array}{c}\text { Pout } \\
\text { no } \\
\text { MPPT }\end{array}$ & $\begin{array}{c}\Delta \text { Pout } \\
\text { no } \\
\text { MPPT }\end{array}$ & $\begin{array}{c}\text { Pout } \\
\text { with } \\
\text { MPPT }\end{array}$ & $\begin{array}{c}\Delta \text { Pout } \\
\text { with } \\
\text { MPPT }\end{array}$ & $\Delta$ \\
\hline 1000 & 292.5 & & 325.3 & & 32.8 \\
\hline & & 3 & & 12.9 & \\
\hline 1050 & 295.5 & & 338.2 & & 42.7 \\
\hline
\end{tabular}

As shown in Table IV, at illumination value of $1000 \mathrm{~W} / \mathrm{m}^{2}$, the difference between obtained power with using and without using MPPT is $32.8 \mathrm{~W}$. After increasing illumination value by $50 \mathrm{~W} / \mathrm{m}^{2}$, the difference between obtained power with using and without using MPPT is 42.7 W using MPPT increases the efficiency as illumination value increases.

\section{The PROPOSED METHOd AND EXPERIMENTAL StUdieS}

This proposed method consists of two stages: in the first stage two panels are connected one buck boost DC/DC converter with MPPT [12], as shown in Fig. 10. In the second stage each of the two panels is connected to one DC/DC converter with MPPT [13], as shown in Fig. 11. Both of the stages are controlled by $\mathrm{P} \& \mathrm{O}$ algorithm under light-available and shadowy conditions.

The experimental set-up consists of four parts. The first part of the PV panel produces DC energy from temperature and radiation. The light that falls sets example for sunny and cloudy (shadowy) condition in PV panels with indoor halogen lamp $(2 \mathrm{~W} \times 500 \mathrm{~W})$. The buck boost DC/DC converter and MPPT produce maximum power with $\mathrm{P} \& \mathrm{O}$ algorithm. The LED strings are used for loading in the system shown in Fig. 9.

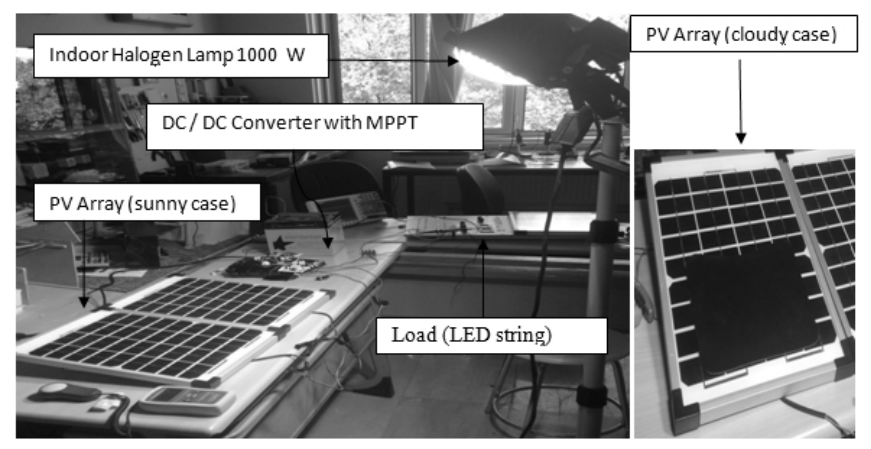

Fig. 9. The system used for observing the output DC power from PV panels under different lighting conditions.

\section{CENTRALIZED DC SYSTEM WITH BUCK-BOOST CONVERTER}

In the first model, the centralized single MPPT including buck-boost converter was connected through two PV panels. In this experimental studies two PV panels were connected in series. The output power obtained from converters have been acquired through two serial connected panels (as shown in Fig. 10) and LED strings were used as a load.

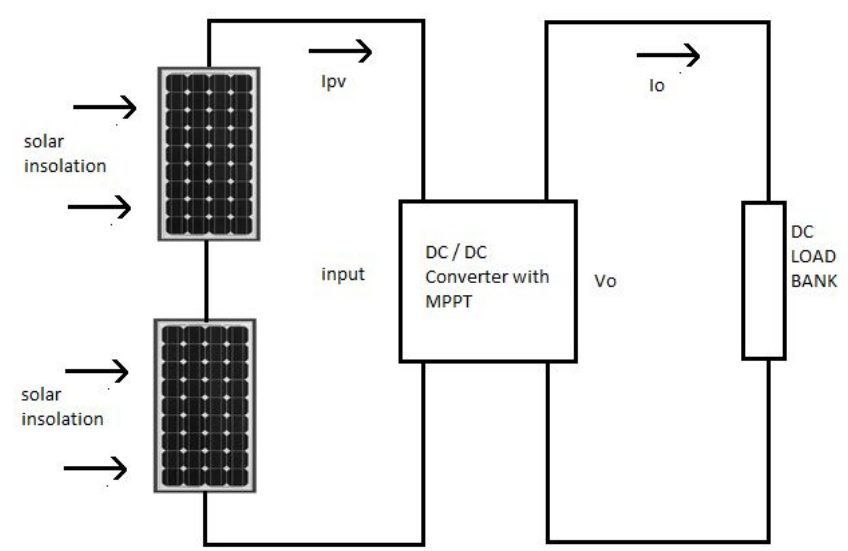

Fig. 10. Centralized MPPT with Buck-Boost converter.

To see the ouput powers, oscilloscope was benefitted. The topology shown in the figure was used to compare 
distributed DC system with centralized DC system in PV energy generation.

\section{DISTRIBUTED DC SYSTEM WITH BUCK-BOOST CONVERTER}

In this experimental studies the second model was used. The Distributed DC System exposed a great similarity with the first method applied in the first model. However, there is a one key difference in this system each panel was connected to MPPT with buck-boost converter. The output power of this system, with the MPP being presented in each one of the panels, was organized in the same way as in the first system deal with above (as seen in Fig. 11).

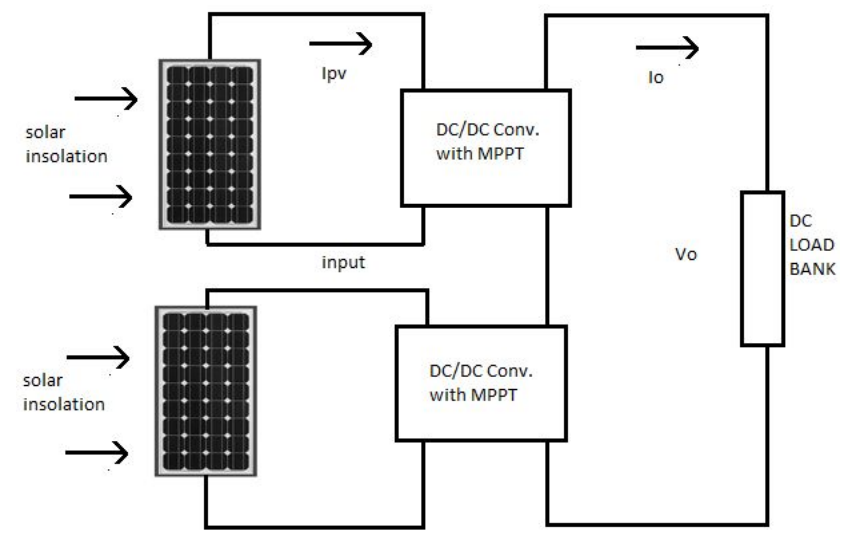

Fig. 11. Distributed MPPT with Buck-Boost converter.

To detect the changes in the output power of each PV panel, a dark object was used and it was used to provide shadowing condition.

\section{RESULTS AND DISCUSSION}

Through the implementation of the irradiation imposed on each method in distinct light levels, the systems in question were mismatched and evaluated. The output voltage produced by each model is indicated in Fig. 12 and Fig. 13.

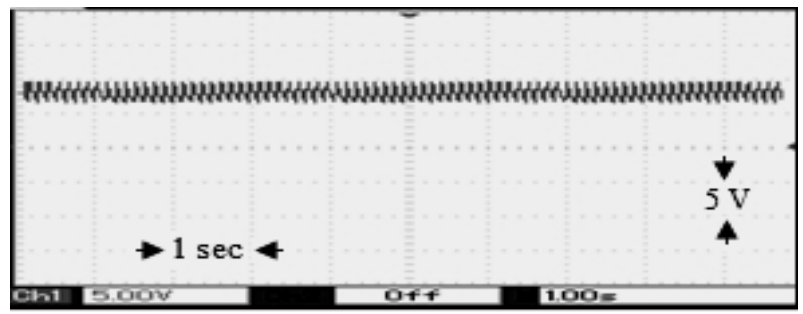

Fig. 12. Output voltage for centralized DC system, sunny condition.

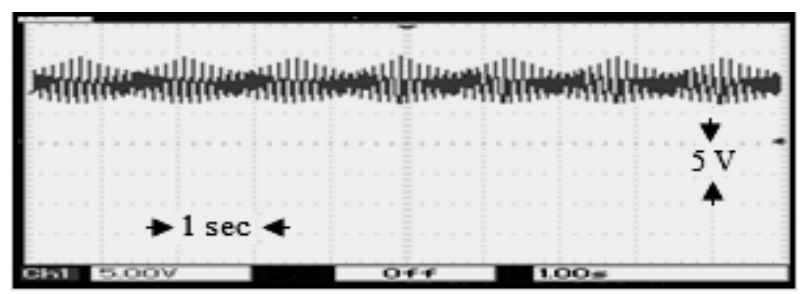

Fig. 13. Output voltage for distributed DC system in PV energy conversion, sunny condition.

Examining two of the sunny conditions are experimented; it gets clear that the waveforms obtained from both of the systems perform a somewhat close tendency. Even though the oscillation observed in the distributed DC system seems to be higher, but this difference is minimal only. In other words, the efficiency of the distributed DC System in sunny situations is slightly more when compared with centralized DC system. This difference could, however, be neglected when the number of the converters used in both of the systems are taken into consideration as there are more converters needed with the distributed DC System in sunny situations than centralized DC System, which is basically a sign of more cost. The centralized DC system would be able to react to small and sensitive changes in sunlight throughout the day, without negative performance issues incurred from occasional clouding. The oscillations acquired are screen outputs of oscilloscope views. All experimental cases are in continuous mode of converters as seen in Fig. 12 and Fig. 13.

The other case shown below demonstrates each model being experimented under a cloudy (shadowy) situation. In this case, each panel was clouded partially by a dark object. Figure 14 and Fig. 15 show the results for both of the sytems under the same condition. As can be observed from the states above the difference obtained between both systems is tremendous when compared with the sunny situation. The output power of the PVs is mostly based on the irradiation condition, and the irradiation level on each panel in this case is different, each unit of MPPT is to perform according to the MPP of the panel. The oscilloscope views given in Fig. 14 and Fig. 15 demonstrate that distributed DC system exhibits a higher performance than centralized DC system.

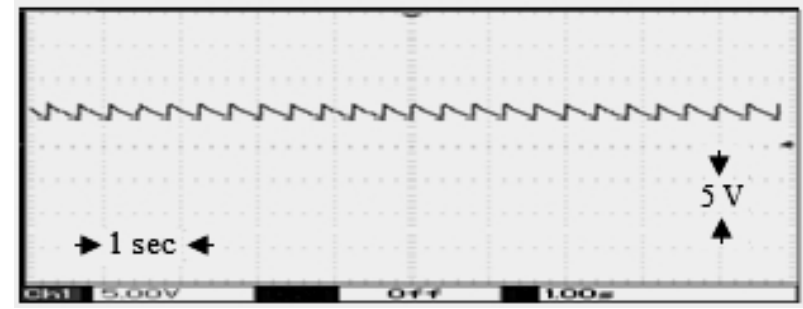

Fig. 14. Output voltage for centralized DC system, cloudy (shadowy) situation.

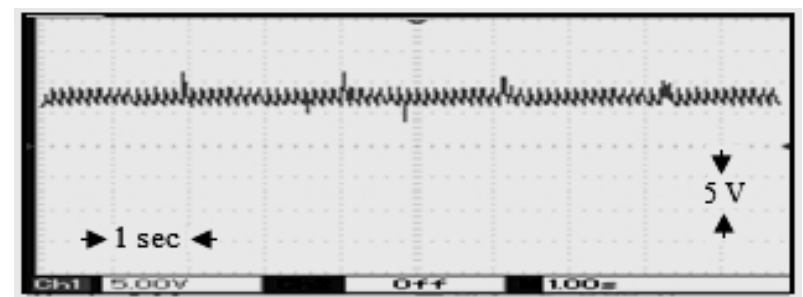

Fig. 15. Output voltage for distributed DC system, cloudy (shadowy) situation.

The distributed DC/DC converter with MPPT system answers better to changes in the source current of its panels, with each panel controlling its power output independently. This leads to improved system stability, as keeping a consistent output saved the other components of the system. In Fig. 16 unfiltered both systems are shown. A more compact vision of the situation explained above is illustrated by the both curves brought together. 


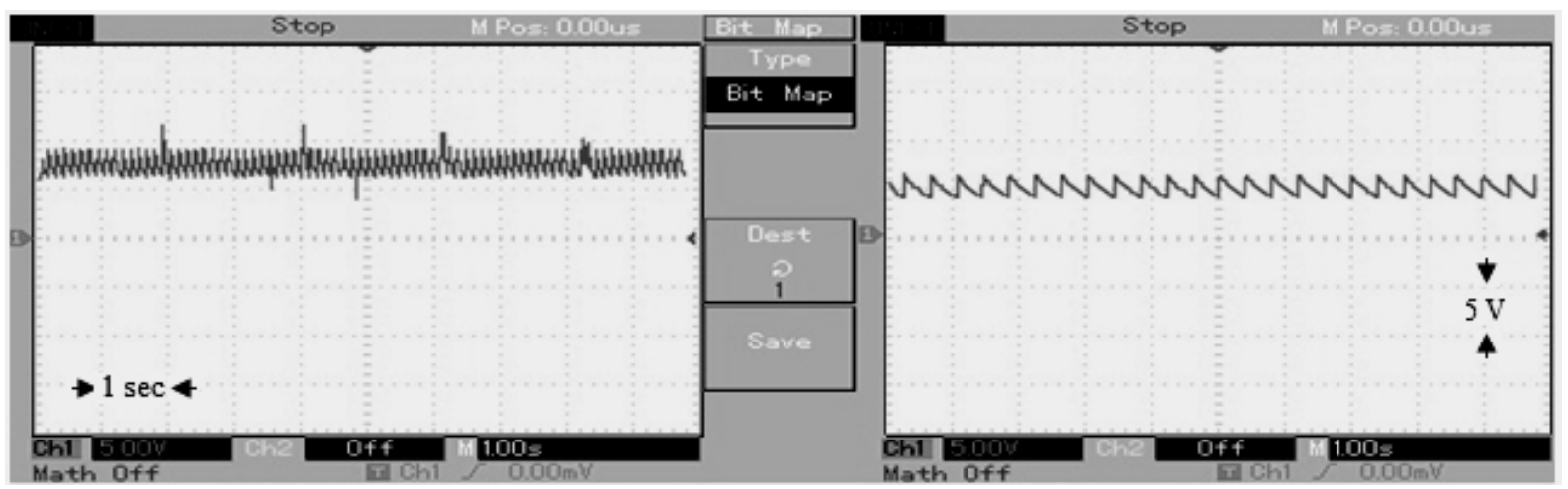

(a)

(b)

Fig. 16. Figures of unfiltered MPPT output voltage during cloudy (shadowy) condition (a) distributed (b) centralized system.

\section{CONCLUSIONS}

In this study; MATLAB simulation of PV generators, which are capable of producing different output powers, are used. In this simulation output power is measured and DC/DC converter is controlled by using MPPT and without using MPPT. In PV energy conversion systems using MPPT increases output power and efficiency. This results in usage of fewer amounts of panels and reduced cost. The systems for photovoltaic panels, a MPPT with DC/DC buck boost converters, and a variable lighting halogen lamp were tested. Making use of these tools, two systems were compared. In the first case, centralized and distributed DC systems were examined under artificial sunny condition. The results obtained from this case showed that distributed DC system had a minimal advantage over centralized DC system in terms of output power. However, this minor difference is to be ignored due to the fact that a distributed DC system would require more of converters, which would typically lead to more cost. In the second case, an artificial cloudy condition was created by the use by using a dark object as a way to cover some part of the PV panel. The results acquired in this situation varied enormously in relation with the first case. The distributed DC system was recorded to have a big advantage over the centralized DC system as the output power is contingent upon the irradiation level changed on each PV panel.

\section{REFERENCES}

[1] S. Panwar, R. P. Saini, "Development and simulation of solar photovoltaic model using Matlab/simulink and its parameter extraction", Int. Conf. Computing and Control Engineering (ICCCE 2012), 2012, pp. 2-5.

[2] J. A. R Hernanz, J. J ve Campayo, "Two photovoltaic cell simulation models in Matlab/Simulink", IJTPE Journal International journal on Technical and Physical Problems of Engineering, pp. 45-47, 2012.

[3] K. H. Hussein, I. Muta, T. Hoshino, M. Osakada, "Maximum photo voltaic power tracking: An Algorithm for Rapidly Changing Atmospheric Conditions", in Proc. Inst. Elect. Eng. -Gen. Trans. Distrib., 1995, pp. 59-64.

[4] D. P. Hohm, M. E. Ropp, "Comparative study of maximum point tracking algorithms using an experimental, prorammable, maximum power point tracking test bed", in Proc. 28th IEEE Photovoltaic Spec. Conf., 2000, pp. 1699-1702.

[5] M. A. Ozcelik, A. S. Yilmaz, "Effect of maximum power point tracking in photovoltaic systems and Its improving and Its application of wireless energy transmission", 1 st. Journal Conf. Clean Energy and Technologies, Paris, France, 2014.

[6] B. Ebrahim, S. Mahmoodieh, H. M. Mahery, "Operational modes and output-voltage-ripple analysis and design considerations of buckboost DC-DC converters", IEE Trans. on Industrial Electronics, vol. 59 , no. $1,2012$.

[7] C. L. Wei, C. H. Chen, K. C. Wu, I. T. Ko, "Design of an averagecurrent-mode non inverting buck-boost dc-dc converter with reduced switching and conduction losses", IEEE Trans on Power Electronics, vol. 27, no. 12, 2012. [Online]. Available: http://dx.doi.org/10.1109/ TPEL.2012.2193144

[8] M. G. Wanzeller, et al., "Current control loop for tracking of maximum power point supplied for photovoltaic array", IEEE Trans. on Instrumentation and Measurement, vol. 53, pp. 1304-1310, 2004 [Online]. Available: http://dx.doi.org/10.1109/TIM.2004.831166

[9] N. Onat, "Recent developments in maximum power point tracking technologies for photovoltaic Systems", Int. Journal of Photoenergy, 2010. [Online]. Available: http://dx.doi.org/10.1155/2010/245316

[10] N. Femia, G. Petrone, G. Spagnuolo, M. Vitelli, Power Electronics and Control Techniques for Maximum Energy Harvesting in Photovoltaic Systems. CRC Press: Boca Raton, 2013, pp. 42-45.

[11] S. Maniktala, Switching power supplies from A to Z. NewnessElsevier: Burlington, 2006

[12] K. Kihyun, L. Kwon, C. Younok, C. Guembae, "A study on the control of buck-boost converter using newton-meth.mppt", Int. Conf Electrical Machines and Systems, Busan, Korea, 2013.

A. Barchowsky, P. P. Jeffrey, et al., "A Comparative study of mppt methods for distributed photovoltaic generation", Innovative Smart Grid Techologies (ISGT), 2012, pp 1-7. [Online]. Available: http://dx.doi.org/10.1109/ISGT.2012.6175798 